\title{
Energy Cost of Paraplegic Locomotion with the ORLAU ParaWalker
}

\author{
A. V. Nene, MB, BS, D Orth, MS (Orth), Mch Orth, ${ }^{1}$ J. H. Patrick, \\ FRCS $^{2}$ \\ ${ }^{1}$ Medical Research Fellow, ${ }^{2}$ Director, The Orthotic Research \& Locomotor \\ Assessment Unit, The Robert fones \& Agnes Hunt Orthopaedic Hospital, \\ Oswestry, Shropshire, SY10 7AG, UK.
}

\section{Summary}

Ten subjects with neurological lesion levels between T4 and T9 have been evaluated in the laboratory at ORLAU using their orthosis in its mechanical form alone (without FES assist). Initially the oxygen consumption at rest was measured. Then the patients were asked to walk (orthotic gait) at their preferred constant steady speed for a period of 5 minutes. Min. $\mathrm{VO}_{2}$ was measured during the exercise. From these readings the energy cost and consumption of the patients' gait was calculated.

Our results show that the ParaWalker allows more efficient walking than do bilateral long leg braces and a paraplegic 3 point gait. It also shows that higher speeds with lower energy cost walking is possible with a different orthotic approach for high or mid thoraic lesion paraplegics. We believe that the energy demands to walk with the ParaWalker are within sustainable limits.

Key words: Paraplegia; Locomotion; Energy Cost; ParaWalker.

\section{Introduction}

Clinicians and Engineers are now internationally involved in the walking rehabilitation of adult paraplegics. They have tried to invent new methods of walking with the aid of orthotics but there is a price to pay in the form of very high energy requirements. Reduction of the energy cost of paraplegic walking is now an important goal.

The ParaWalker (name given to the hip guidance orthosis in routine clinical supply) has been in use for adult traumatic paraplegics for about 5 years. Contrary to the previous experience of orthotic paraplegic walking, a recent survey (Summers et al., 1986) showed that $85^{\circ}{ }_{0}$ of the patients were still regularly using their ParaWalker at follow-up, on average 20 months from the date of supply of their orthosis. They all had a complete traumatic spinal cord injury between C8 and T12. This compares very favourably with a number of earlier reviews of adult paraplegics using bilateral long leg calipers and crutches to perform swing through or swing to gait.

The object of the present study was to calculate the energy requirements of 
Table I Subjects

\begin{tabular}{rlccccc}
\hline No. & Subject & $\begin{array}{c}\text { Age } \\
\text { years }\end{array}$ & $\begin{array}{c}\text { Lesion } \\
\text { level }\end{array}$ & $\begin{array}{c}\text { Weight with } \\
\text { orthosis } \\
\text { kgs. }\end{array}$ & $\begin{array}{c}\text { Duration of } \\
\text { paraplegia } \\
\text { years/months }\end{array}$ & $\begin{array}{c}\text { Duration of } \\
\text { ParaWalker } \\
\text { use months }\end{array}$ \\
\hline 1 & MG & 27 & T4 & $75 \cdot 8$ & $4 / 9$ & 45 \\
2 & AB & 28 & T4 & $72 \cdot 73$ & $9 / 5$ & 2 \\
3 & WF & 23 & T5 & $67 \cdot 72$ & $2 / 3$ & 11 \\
4 & PL & 27 & T6 & $103 \cdot 37$ & $7 / 3$ & 14 \\
5 & DL & 25 & T6 & 90 & $9 / 1$ & 24 \\
6 & JN & 28 & T6 & $66 \cdot 35$ & $4 / 6$ & 15 \\
7 & NH & 23 & T7 & $84 \cdot 83$ & $6 / 2$ & 38 \\
8 & MS & 28 & T7 & $64 \cdot 55$ & $3 / 5$ & 24 \\
9 & J MCK & 33 & T7 & $73 \cdot 6$ & $5 / 0$ & 15 \\
10 & JH & 31 & T9 & 77.86 & & \\
\hline
\end{tabular}

patients walking in the ParaWalker; then to compare these values to those reported using conventional bracing. We also wished to form a baseline for the further study of energy requirements using the mechanical (ParaWalker) and the Functional Electrical Stimulation 'Hybrid' Orthosis.

ORLAU has, in the past, used the Physiological Cost Index (PCI) as an indicator of energy expenditure of handicapped gait (Butler et al., 1984). In cases of traumatic paraplegia with complete high thoracic level injury, absence or incomplete function of the sympathetic nervous system can result in an unpredictable heart rate response; consequently for greater accuracy evaluation of the energy cost of the ParaWalker gait was performed by direct measurement of oxygen consumption.

\section{Patients and methods}

Ten subjects participated in this study (Table I). All were traumatic complete paraplegics with neurological levels between T4 and T9. Their age ranged between 23 and 33 years with a mean of 27.3 years. Duration of paraplegia ranged from 2 years and 3 months to 9 years and 6 months. All were trained ParaWalker users, the period after supply ranging from 2 months to 45 months with a mean of 20.6 months. None of them had any symptoms relating to their respiratory function.

\section{Oxylog-Portable oxygen consumption meter}

The Oxylog is a portable instrument designed to measure the oxygen consumption of an ambulatory subject (Fig. 1).

The subject wears a face mask with inspiratory and expiratory valves to which a turbine type flow meter is attached to measure inspiratory volume. Expired air passes through a flexible pipe connected to the instrument.

The $\mathrm{PO}_{2}$ difference between the inspired and expired air is measured in the instrument and the volume of oxygen extracted from the air breathed is calculated and displayed as cumulative total volume and minute volume $\left(\mathrm{Min} \mathrm{VO}_{2}\right)$.

The basic formula which the instrument uses to calculate the volume of oxygen consumed is 


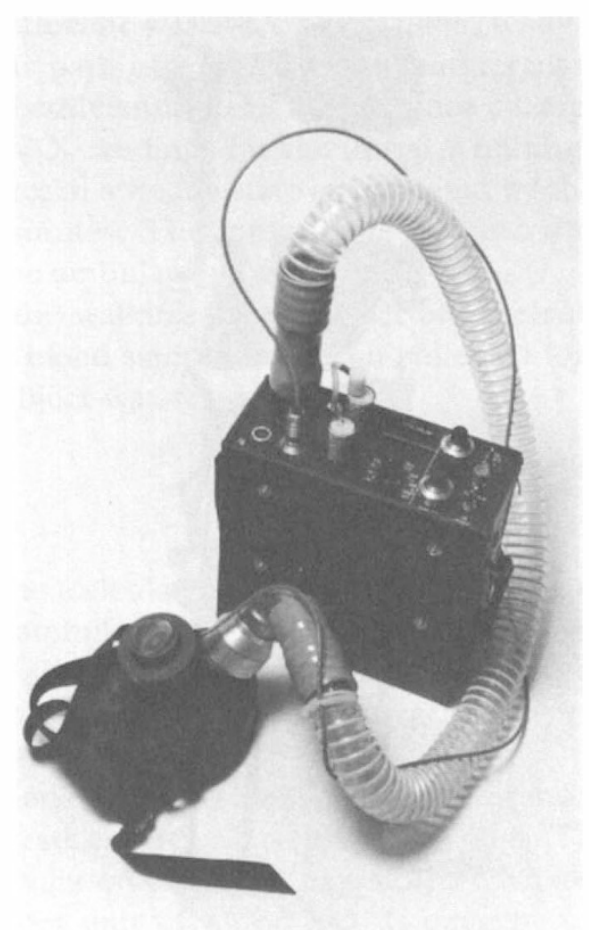

Figure 1 The Oxylog-Portable oxygen consumption meter.

$\underset{\text { Vol } \mathrm{O}_{2} \text { Consumed }}{(\text { N.T.P. Dry })}=\frac{\left(\mathrm{PO}_{2} \text { inspired air }-\mathrm{PO}_{2} \text { expired air }\right) \times \text { Vol. inspired air }}{760}$

This formula makes some assumptions namely: (a) The volume of inspired air has been corrected to 0 dry at the pressure of experiment. This is achieved in the instrument by measuring the temperature of the flow meter with a thermistor and using this temperature to correct the volume of air assuming $50 \%$ relative humidity. Variations in humidity above and below $50 \%$ will cause only a small error in readings. (b) The $\mathrm{PO}_{2}$ of both inspired and expired air is measured on dry samples of air. This is achieved by passing them through drying tubes containing Drierite $\left(\mathrm{CaSO}_{4}\right.$ anhydrous) before analysis in the instrument. (c) The volume of oxygen given by the formula is only correct if the respiratory quotient $(R Q)$ equals 1 . In practice changes in $R Q$ will introduce small errors. These errors can be minimised if this reading is to be used to calculate energy expenditure. (Manufacturer's Instruction Manual).

Calibration of the oxygen sensors for atmospheric $\mathrm{PO}_{2}$ need to be checked before each experiment.

\section{ParaWalker}

This orthosis enables paraplegics to walk reciprocally with crutches over a variety of surfaces and inclines (Fig. 2). 


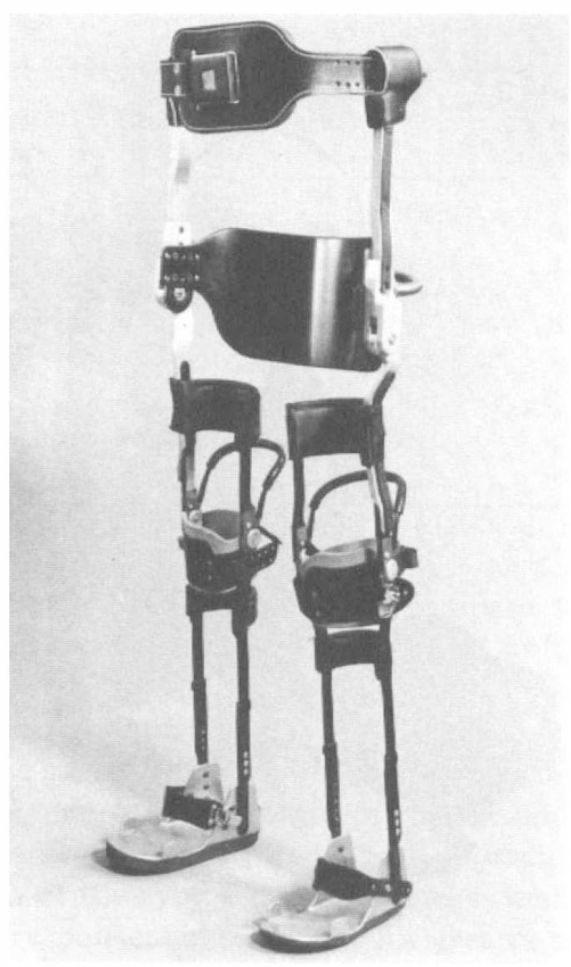

Figure 2 The ParaWalker.

The principles of the hip guidance articulation used in the ParaWalker have been extensively described by Rose (1979, 1980), Stallard et al., (1986).

This orthosis has a unique combination of:

1. Rigid body brace which resists lower limb adduction/abduction.

2. Low friction hip joints with adjustable flexion/extension stops.

3. Easily operated hip and knee joint locks which facilitate sitting and standing.

4. Simply operated fastening mechanisms which ease doff and don.

5. A high degree of mechanical safety and reliability which reduces maintainence costs.

6. Modular construction which ensures correct specification and limits cost to those of conventional, less effective devices.

\section{Method}

On arrival in the Department, each subject was asked to don the orthosis and then to rest in his wheelchair. After he had recovered from the efforts of this activity a venous blood sample was taken for lactate level estimation. The Oxylog face mask was then fitted and oxygen consumption per minute $\left(\mathrm{Min} \mathrm{VO}_{2}\right)$ was measured for 5 consecutive minutes. The mean value of these readings was considered as the resting oxygen consumption.

Each subject was then asked to stand up in his orthosis. After he had recovered 
completely from this effort he was asked to walk at a steady pace, at his preferred speed round a circular path of 15.25 metre circumference. $\mathrm{Min} \mathrm{VO}_{2}$ readings were taken for 5 consecutive minutes. The distance covered in those 5 minutes was also noted. $\mathrm{Min} \mathrm{VO}_{2}$ readings for the initial 2 minutes were discounted to enable the subject to reach a steady state as indicated by the fairly constant Min $\mathrm{VO}_{2}$ for the next 3 minutes. The mean value of these three readings was calculated to establish the ambulatory $\mathrm{Min} \mathrm{VO}_{2}$.

Immediately after the walking excercise period, the subjects rested in their wheelchair. A venous blood sample was again collected for lactate level estimation as soon as the subject was seated.

\section{Results}

The average speed was calculated from the distance covered in the 5 minute walking period. The ambulatory Oxygen consumption figure when divided by subject's weight gave the oxygen consumption per kilogram mass per minute. Dividing this figure by the speed gave the oxygen cost per kilogram per meter covered.

Under basal conditions the RQ is 0.82 in older children and adults (Consolazio et al., 1963) and moderate excercise has little effect on it. The following equation lends itself to the calculation of energy expenditure where $\mathrm{E}$ stands for energy expenditure (in kcal per unit of time): $\mathrm{VO}_{2}$ is oxygen consumption (in $\mathrm{L}$ per unit of time).

$$
\mathrm{E}=4.825 \mathrm{VO}_{2} \quad \text { (Geigy Scientific Tables, 1981). }
$$

Using this equation energy in kcal was determined for each subject. For conversion of these readings into SI units the following formula was used:

$$
1 \text { calorie }=4 \cdot 184 \mathrm{~J} \quad \text { (Anderton and Bigg, 1972). }
$$

For comparative analysis, results from the previously published work were also similarly converted into SI Units. Table II shows the results obtained with the subjects ambulating using the ParaWalker. Walking speed varied from $0 \cdot 133$ $\mathrm{m} \mathrm{s}^{-1}$ to $0.349 \mathrm{~m} \mathrm{~s}^{-1}$ with a mean speed of $0.214 \mathrm{~m} \mathrm{~s}^{-1}$.

A distinction is made between the energy consumption and energy cost. Consumption being the energy consumed per unit of time whilst cost is the energy required to ambulate a unit distance. The values for both were quite variable. The mean energy consumption was $3 \cdot 1 \mathrm{~J} \mathrm{Kg}^{-1} \mathrm{~s}^{-1}$, with a range between 4.34 and $2.204 \mathrm{~J} \mathrm{~kg}^{-1} \mathrm{~s}^{-1}$. The mean energy cost was $16 \mathrm{~J} \mathrm{~kg}^{-1} \mathrm{~m}^{-1}$ (min $8.07 \mathrm{~J} \mathrm{~kg}^{-1} \mathrm{~m}^{-1}$ and $\max 28 \cdot 87 \mathrm{~J} \mathrm{~kg}^{-1} \mathrm{~m}^{-1}$ ).

\section{Discussion}

All the subjects in the present series ambulated with the help of crutches. Merkel and associates (1985) mention that their subjects with mid thoracic level lesion were unable to use crutches. Not all authors have clarified the type of walking aid used in conjunction with the orthoses. 
Gordon and Vanderwalde (1956) were the first to study energy requirements of paraplegic locomotion. They found that during ambulation the subjects utilised up to 6 times their basal energy levels. They felt that the subjects would have been unable to sustain this high energy demand for long periods. Gordon (1956) felt that the subjects with thoracic level lesion probably would not be able to ambulate successfully using braces. Clinkingsbeard and his associates (1964) also came to similar conclusions.

Following these pioneering publications other studies by Chantraine et al., (1984), Waters et al., (1985), Huang et al., (1979), Merkel et al., (1984, 1985) and Cerney et al., (1980) are noted in the literature. The majority of their subjects (including Clinkingbeard's) had either very low thoracic or upper lumbar level lesions. One of the subjects in Clinkingbeard's series had a cauda equina lesion. Waters et al., (1985) do not specify the level of injury in their group of subjects.

Only 6 subjects out of 28 from the above mentioned series had mid thoracic level of injury. All subjects in the present series had lesions between T4-T9. Table III shows a paper comparison of subjects with mid thoracic level lesion from the historic and the present series. We note that Clinkingbeard and his associates (1984) had only two subjects with T4 lesions who were accustomed walkers. Their speed was very slow with extremely high energy cost per metre. From these results it is quite understandable that they felt high thoracic paraplegia was incompatible with ambulation. Results of the subjects in the present series show faster speed with lower energy costs than the comparable subjects from the other series.

Figures $3 \mathrm{~A}$ to $3 \mathrm{C}$ show the results of the present series compared with other

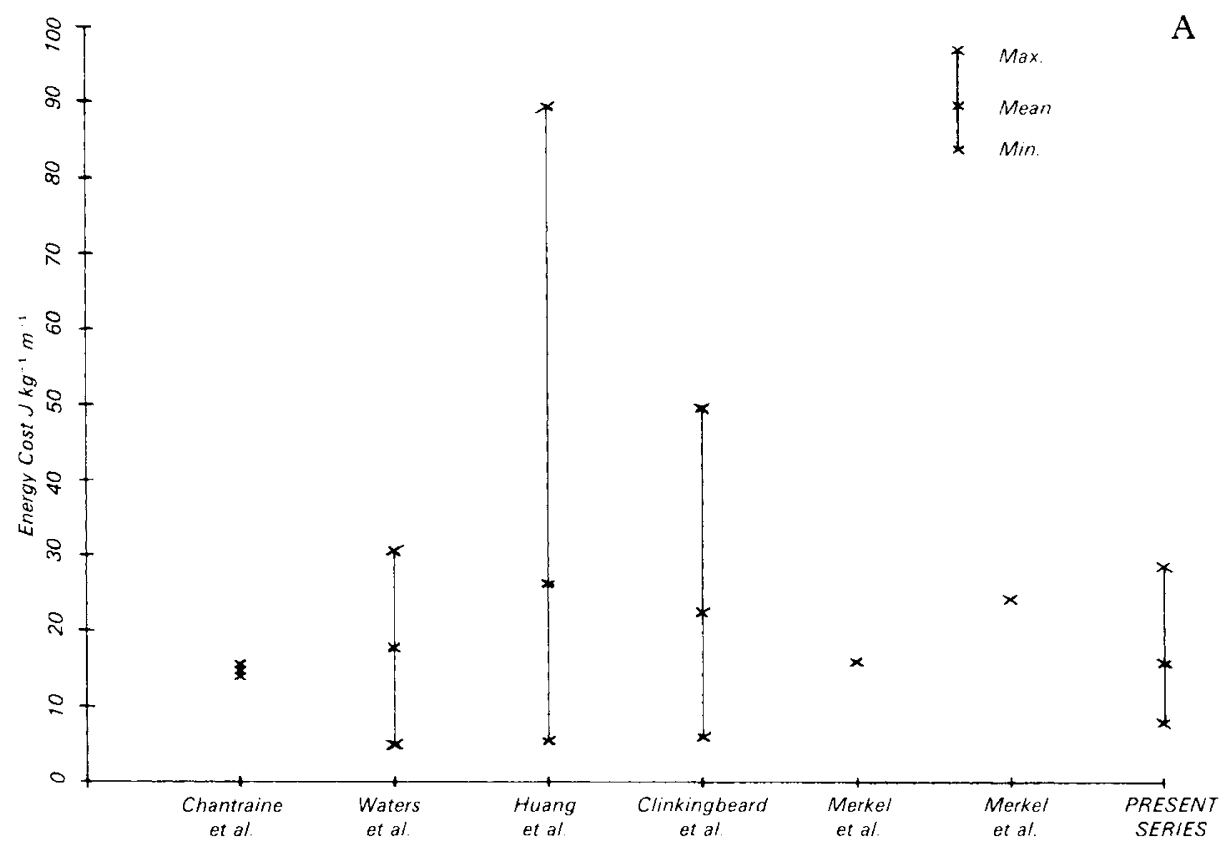



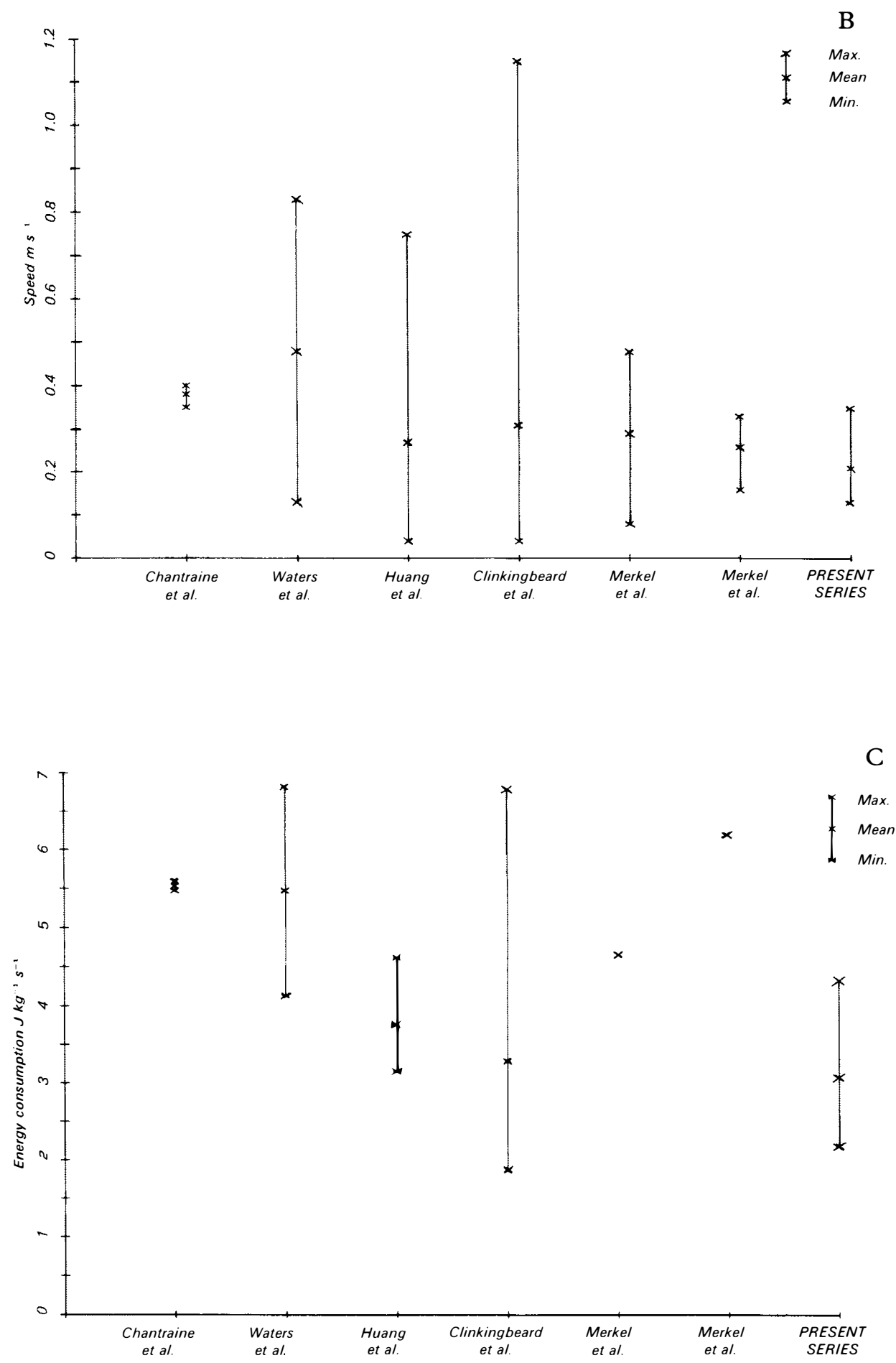

Figure 3A to 3C Comparison of energy cost, energy consumption and speed of the subjects (Total subject complement) in the historic series to those of the present series. 
Table II Results

\begin{tabular}{clccc}
\hline No. & Subject & $\begin{array}{c}\text { Speed } \\
\mathrm{m} \mathrm{s}^{-1}\end{array}$ & $\begin{array}{c}\text { Energy consumption } \\
\mathrm{J} \mathrm{kg}^{-1} \mathrm{~s}^{-1}\end{array}$ & $\begin{array}{c}\text { Energy cost } \\
\mathrm{J} \mathrm{kg}^{-1} \mathrm{~m}^{-1}\end{array}$ \\
\hline 1 & MG & $0 \cdot 248$ & $2 \cdot 587$ & $10 \cdot 29$ \\
2 & AB & $0 \cdot 133$ & $3 \cdot 529$ & $26 \cdot 45$ \\
3 & WF & $0 \cdot 349$ & $2 \cdot 880$ & $8 \cdot 07$ \\
4 & PL & $0 \cdot 212$ & $3 \cdot 448$ & $16 \cdot 15$ \\
5 & DL & $0 \cdot 144$ & $2 \cdot 850$ & $19 \cdot 58$ \\
6 & JN & $0 \cdot 241$ & $2 \cdot 434$ & $10 \cdot 08$ \\
7 & NH & $0 \cdot 133$ & $3 \cdot 856$ & $28 \cdot 87$ \\
8 & MS & $0 \cdot 229$ & $2 \cdot 866$ & 12.52 \\
9 & J MCK & $0 \cdot 254$ & $4 \cdot 340$ & 16.96 \\
10 & JH & $0 \cdot 197$ & $2 \cdot 204$ & 11.10 \\
& Mean & $0 \cdot 214$ & $3 \cdot 1$ & 16.00 \\
\hline
\end{tabular}

Table III Results of comparable subjects in different series

\begin{tabular}{lcccc}
\hline Series & Lesion level & $\begin{array}{c}\text { Speed } \\
\mathrm{m} \mathrm{s}^{-1}\end{array}$ & $\begin{array}{c}\text { Energy consumption } \\
\mathrm{J} \mathrm{kg}^{-1} \mathrm{~s}^{-1}\end{array}$ & $\begin{array}{c}\text { Energy cost } \\
\mathrm{J} \mathrm{kg}^{-1} \mathrm{~m}^{-1}\end{array}$ \\
\hline Huang et al. & $\mathrm{T} 4$ & $0 \cdot 178$ & $3 \cdot 60$ & $18 \cdot 16$ \\
Clinkingbeard et al. & $\mathrm{T} 4$ & $0 \cdot 070$ & $2 \cdot 58$ & $35 \cdot 92$ \\
& $\mathrm{~T} 4$ & $0 \cdot 040$ & $1 \cdot 87$ & $44 \cdot 80$ \\
Merkel et al. & T6-T9 & $0 \cdot 172$ & $3 \cdot 83$ & $22 \cdot 37$ \\
Present series & (3 sub) & & $3 \cdot 10$ & $16 \cdot 00$ \\
& T4-T9 & $0 \cdot 214$ & & \\
\hline
\end{tabular}

series (the total patient complement). It can be seen that the energy cost per metre for mid thoracic lesions in the ParaWalker subjects is one of the lowest. It is also noted that the speed was slowest too but this would be because of the reciprocal nature of locomotion. Energy consumption per unit time was also lowest in this group.

Blessey (1978) studied energy requirements of normal walking and found energy consumption to be $4.355 \mathrm{~J} \mathrm{~kg}^{-1} \mathrm{~s}^{-1}$, energy cost $3.25 \mathrm{~J} \mathrm{~kg}^{-1} \mathrm{~m}^{-1}$ and speed $1.37 \mathrm{~m} \mathrm{~s}^{-1}$. ParaWalker subjects consumed $3 \cdot 1 \mathrm{~J} \mathrm{~kg}^{-1} \mathrm{~s}^{-1}$, with a speed of $0.213 \mathrm{~m} \mathrm{~s}^{-1}$ at the cost of $16.0 \mathrm{~J} \mathrm{~kg}^{-1} \mathrm{~m}^{-1}$. The energy cost of unit distance covered was 4.9 times the normal cost in the ParaWalker group with the average speed being $15.5 \%$ of human normal walking speed. Merkel et al., (1985) found that the energy cost of their subjects with low or mid thoracic lesions was from 8 to 9 times more than for normal walking while in subjects with high thoracic lesion it was 25 times more. Three of our subjects (MS, DL, JM) regularly cover about 0.5 to 1 Kilometre, one other subject (WF) can walk up to 2 Kilometre.

The energy consumption for subjects in the present series was approximately 3.45 times their resting level. This rate is comparable to other historical series except that of Gordon and Vanderwalde (1956) who found ambulatory energy consumption to be up to 6 times the resting level.

Clinkingbeard et al., (1964) in their study, concluded that lower levels of neurological lesion required lower energy for ambulation (per unit distance). They found that the patient's energy consumption (per unit time) increased with increased speed. They also found that the energy cost lowers as the duration 
of training increases. Analysis of the results in the present series shows no relationship between level of lesion, energy consumption, duration of use of the orthosis and speed. (Figs $4 \mathrm{~A}$ to $4 \mathrm{G}$ ). It can be deduced that the efficiency of the ParaWalker gait lies in the intrinisic stability provided by the orthosis. It

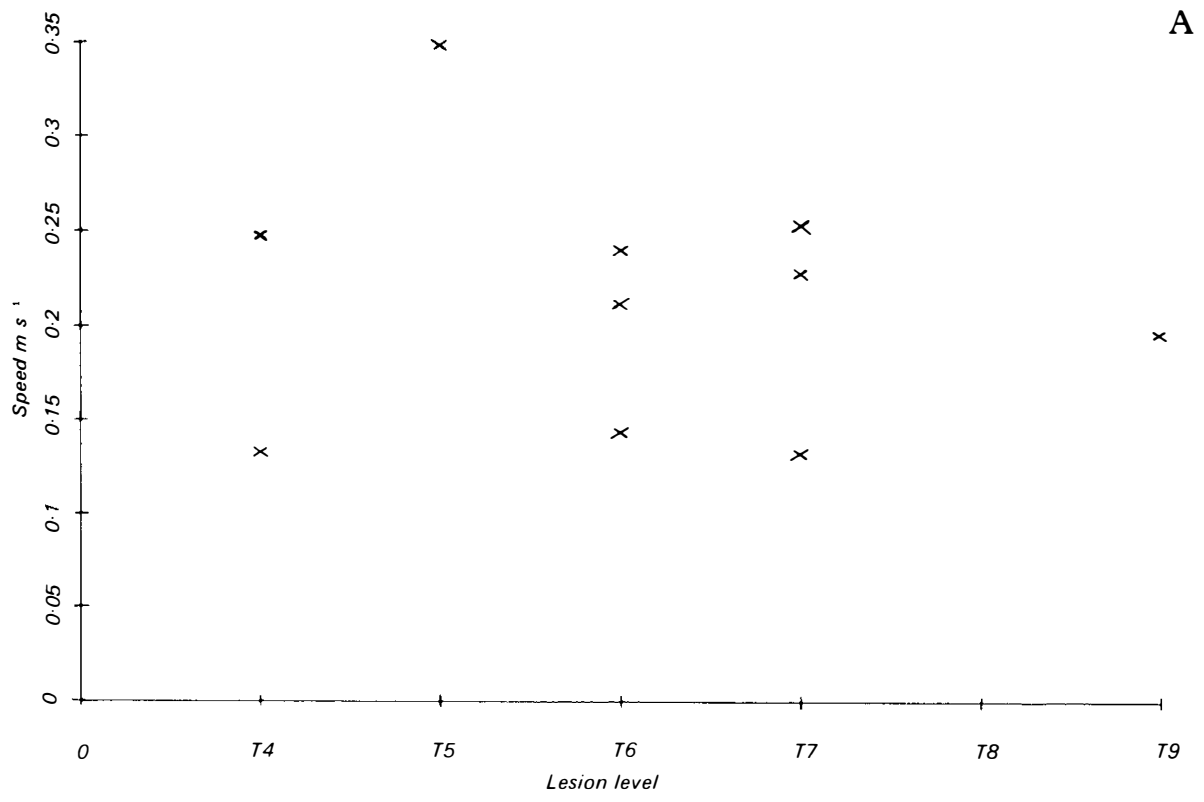

A

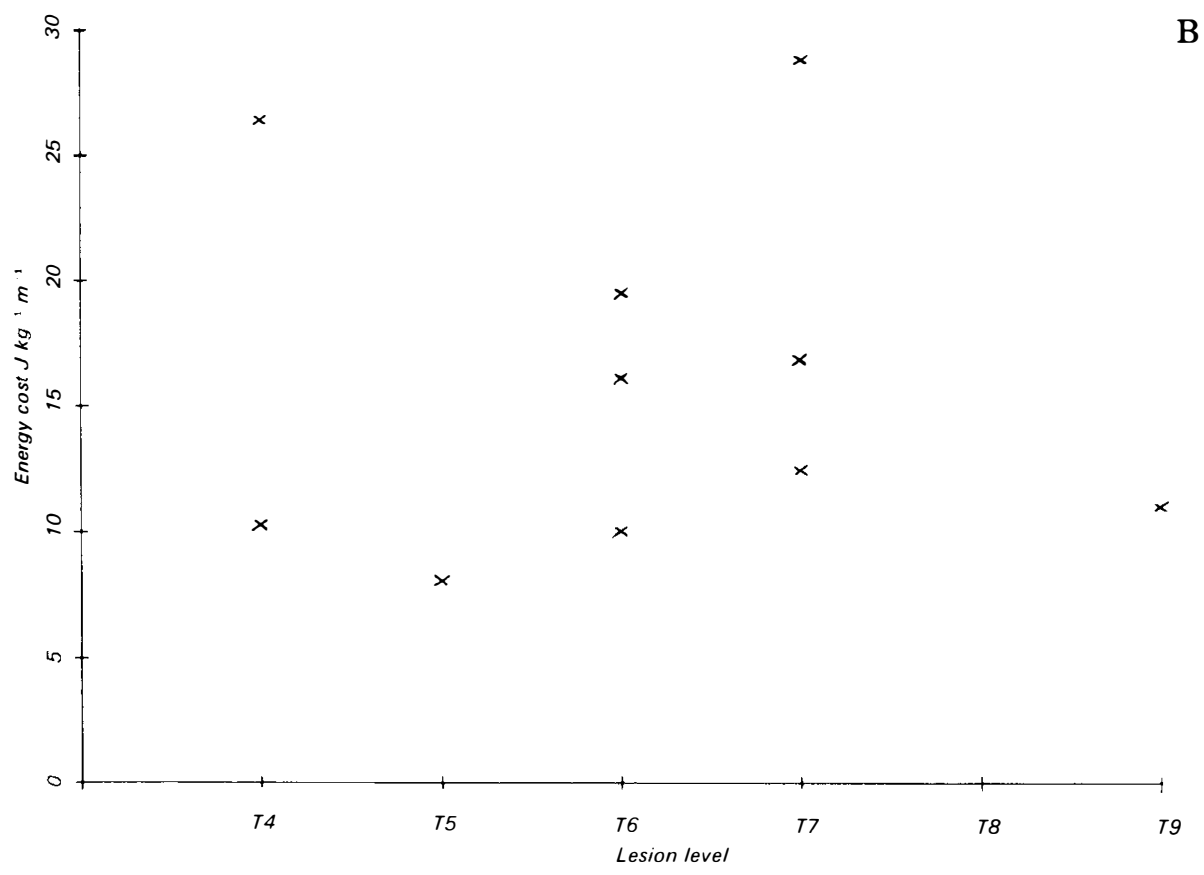


14 PARAPLEGIA
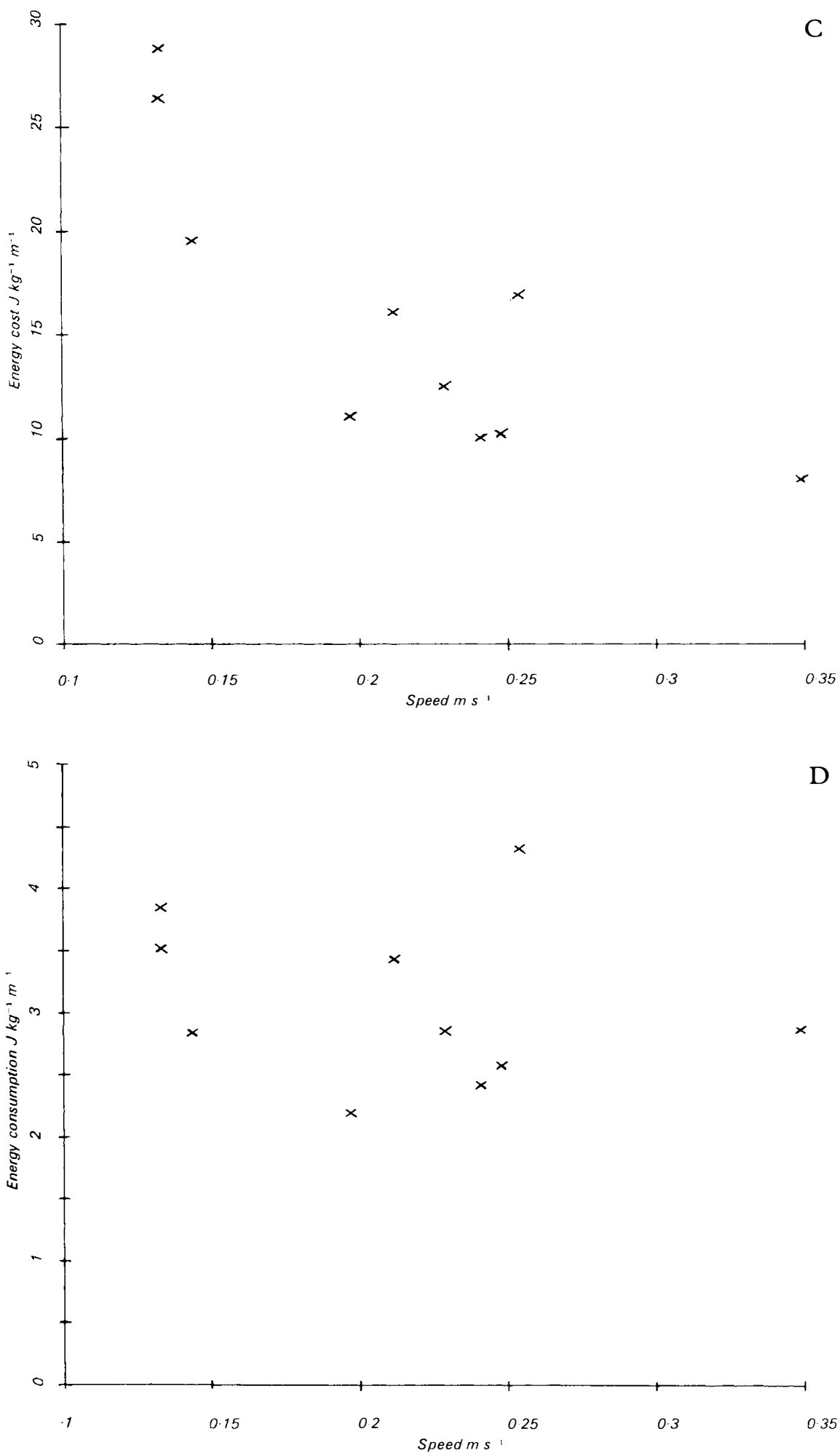


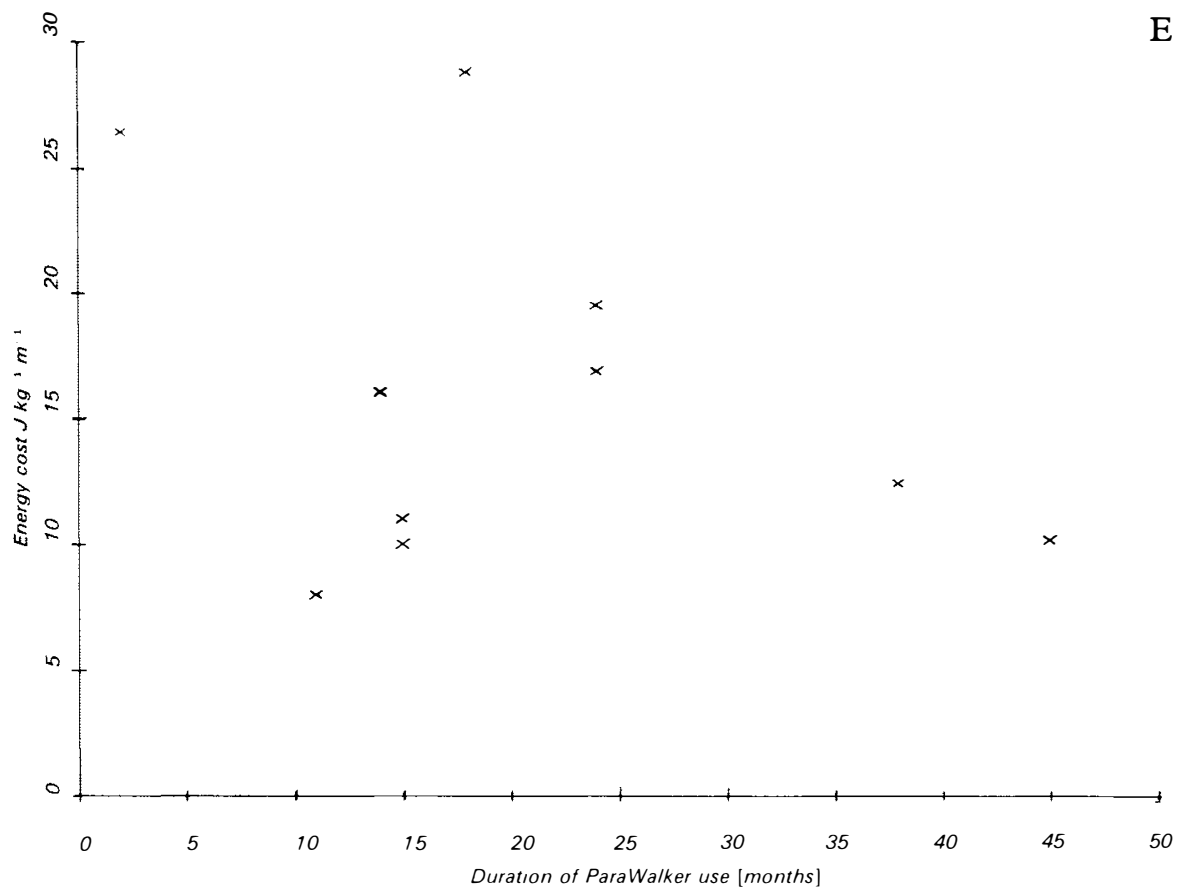

E

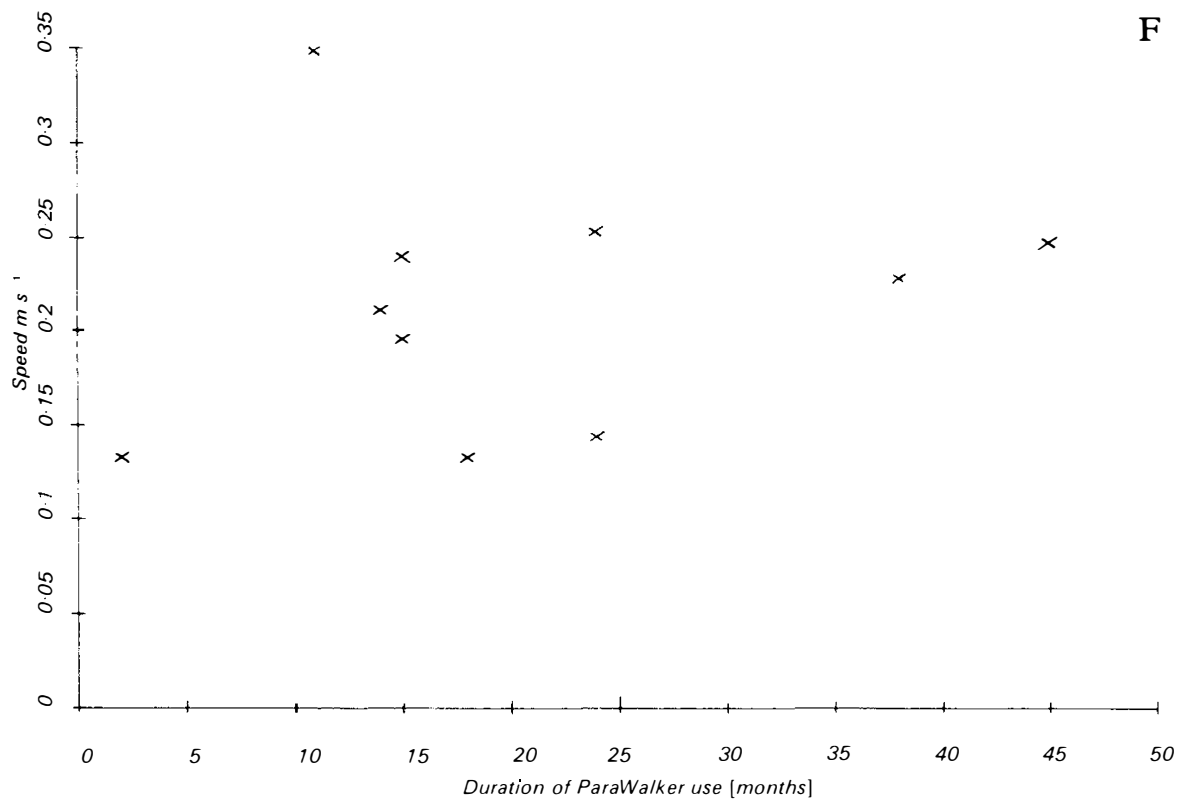




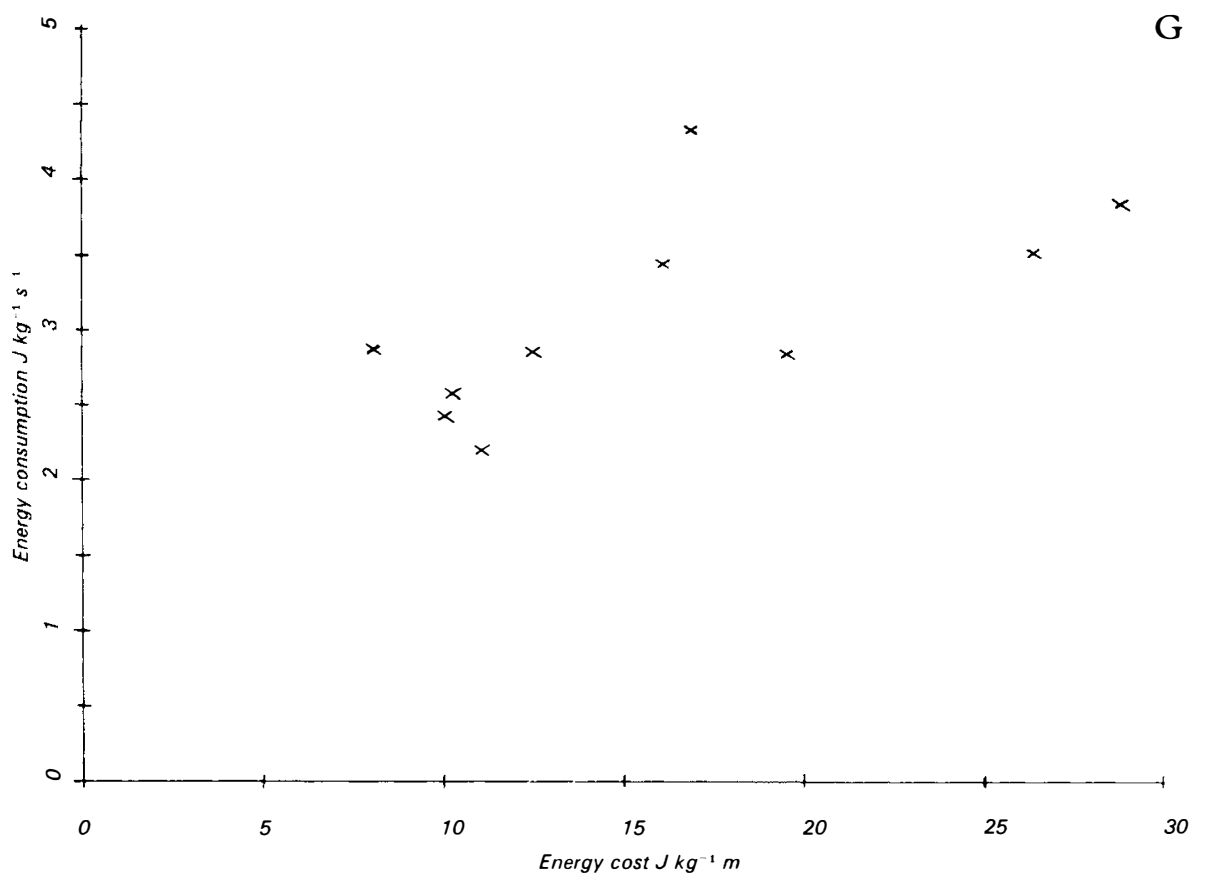

Figure 4A to 4G Comparison of various parameters in the present series.

supports the patients' hips and trunk adequately and they do not have to spend energy stabilising and maintaining balance. Although the ParaWalker offers some trunkal support it should not be considered as a spinal orthosis.

All the subjects showed a rise in their post exercise lactate levels (Fig. 5). Two subjects $(\mathrm{JM}, \mathrm{JH})$ had smaller increases than the rest. No explanation could be obtained for these differences by comparison with the other variables monitored in the study.

During exercise of moderate intensity, anaerobic processes contribute to the energy output at the beginning of the exercise until the aerobic oxidation can take over and completely cover the energy demand. Any lactic acid produced in this process diffuses into the circulation and can be traced in the venous blood. The amount produced will depend upon the bulk of the active musculature. (Astrand and Rodahl 1970).

The endurance capacity is characterised by the exercise intensity at which the energy demands can be met in total by oxidative metabolism following the initial production of lactate. The transition area between the purely aerobic and partially anaerobic energy supply was named aerobic-anaerobic threshold of the exercising musculature. The lactic acid concentration level of $4 \mathrm{mmol}^{-1}$ in peripheral blood during gradual increasing workloads can be considered as the aerobic-anaerobic threshold. (Heck et al., 1985). This threshold value was determined from the observation that endurance trained athletes could tolerate respective workloads for longer periods and any higher workloads normally resulted in a continued increase in the lactate concentration.

Although the average rise in the lactate was to $3.448 \mathrm{mmol}^{-1}$ (range $2 \cdot 3$ to 


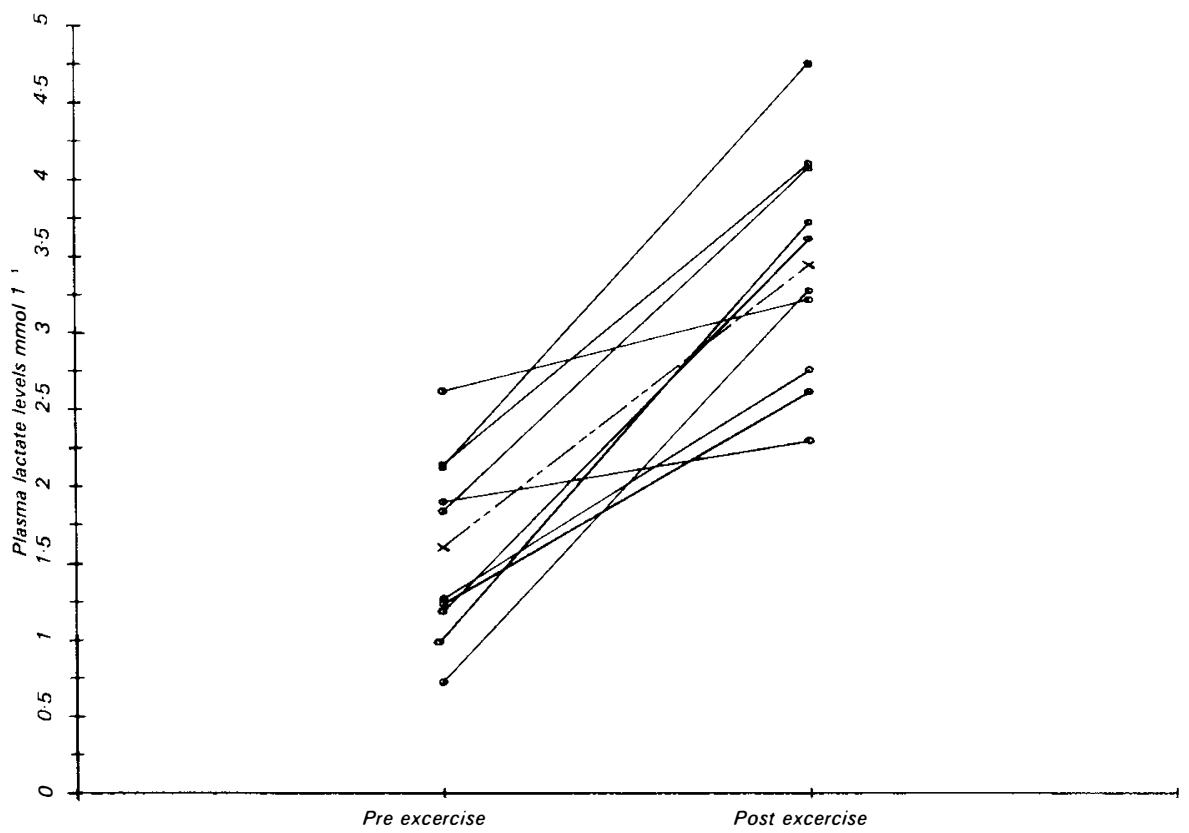

Figure 5 Pre and post exercise values of plasma lactate in 10 subjects of the present series.

$4.76 \mathrm{mmol} \mathrm{l}^{-1}$ ), further work is necessary to determine the aerobic-anaerobic threshold value for upper extremity exercise workloads.

Recovery data was collected for two subjects (MS, JH) in the survey. Oxygen debt was repayed almost completely within 15 minutes but lactate level remained higher than the resting level. Huang et al. (1979) in their conclusion found that the blood lactate level increased despite a relatively small oxygen debt.

\section{Conclusion}

This work shows that the ParaWalker allows more efficient walking than does bilateral long leg braces. It also shows that higher speed with lower energy cost walking is possible with suitable orthotic treatment for high or mid thoracic lesion paraplegics. It has been demonstrated that these subjects dictate their own energy consumption and energy cost. These parameters do not depend upon the level of neurological lesion. We believe that the energy demands to walk with the ParaWalker are within sustainable limits; and are beginning to challenge the traditional advice to paraplegics with thoracic lesions to opt for a wheelchair life.

\section{Acknowledgements}

We are grateful to Messrs P. K. Morgan Ltd, for their kind loan of the Oxylog, without it the entire project would not have been possible. We are also thankful to Miss C. A. Morris for her untiring secretarial help. 


\section{References}

Anderton P, Bigg PH (1972) Changing to metric system. Conversion factors, symbols and definitions, National Physical Laboratory, HM Stationery Office, London. p 25.

Astrad PO, Rodahl K 1970. Textbook of Work Physiology. McGraw-Hill, New York.

BlesSEy R 1978. Energy cost of normal walking. Orthopedic Clinics of North America 9:356-358.

Butler P, Engelbrecht M, Major R, Tait J, Stallard J, Patrick J 1984 Physiological cost index of walking for normal children and its use as an indicator of physical handicap. Developmental Medicine and Child Neurology 26:607-612.

Cerny K, Waters R, Hislop H, Perry J (1980) Walking and wheelchair energetics in persons with paraplegia. Physical Therapy 60:1133-1139.

Chaintraine A, Crielaard J M, Onkelinx A, Pirnay F 1984 Energy expenditure of ambulation in paraplegics; effects of long term use of bracing. Paraplegia 22:173-181.

Clinkingbeard JR, Gesten JW, Hoehn D 1964 Energy cost of ambulation in traumatic paraplegic. American fournal of Physical Medicine 43:157-165.

Consolazio et al. 1963 Physiological measurements of metabolic functions in man. McGraw-Hill, New York p 315.

Geigy Scientific Tables 1981 Vol. 1, 8th Edition, Ciba-Geigy, pp 229-231.

Gordon, EE, 1956 Physiological approach to ambulation in paraplegia. Fournal of the American Medical Association 161:686-688.

Gordon, EE, VANDERWALDE, H 1956 Energy requirements in paraplegic ambulation. Archives of Physical Medicine and Rehabilitation 37:276-285.

Heck H, Mader A, Hess G, Mucke S, Muller R, Hollmann W 1985 Justification of the 4$\mathrm{mmol} 1$ lactate threshold. International fournal of Sports Medicine 6:117-130.

Huang CT, Kuhlemeier KV, Moore MB, Fine PR 1979 Energy cost of ambulation in paraplegic patients using Craig Scott braces. Archives of Physical Medicine and Rehabilitation 60:595-600.

Merkel KD, Miller NE, Mbrritt JL 1985 Energy expenditure in patients with low, mid or high thoracic paraplegia using Scott Craig knee ankle foot orthoses. Mayo Clinical Proceedings 60:165-168.

Merkel KD, Miller NE, Westbrooke PR, Merritt, JL 1984 Energy expenditure of paraplegic patients standing and walking with two knee ankle foot orthoses. Archives of Physical Medicine and Rehabilitation 65:121-124.

Oxylog-Instruction Manual, PK Morgan Ltd.

ROSE GK 1979 Principles and practice of hip guidance articulations. Prosthetics and Orthotics International 3:37-43.

RosE GK 1980 Orthoses for the severely handicapped-rational or empirical choice. Physiotherapy 66:76-81.

Stallard J, Major RE, Poiner R, Farmer IR, Jones N 1986 Engineering design consideration of the ORLAU ParaWalker and FES hybrid system. Engineering in Medicine. 15:123-129.

Summers BN, McClelland MR, Patrick JH, El Masri WS 1986 A clinical review of the adult hip guidance orthosis. Paper read at the Scientific Meeting of the IMSP, Oslo, Norway, August 1986

WATERS RL, and LUNSFORD BR 1985 Energy cost of paraplegia locomotion. fournal of Bone and foint Surgery 76A:1245-1250. 